\title{
Adverse Effects of Soriatane on Rats Enterocytes: Light Microscopy and Ultrastructural Studies
}

\author{
Laila A. Hummadi* \\ Biology Department, Science Faculty for Girls, King Abdul-Aziz University, Saudi Arabia
}

\begin{abstract}
Soriatane (Acitretin) drug is a synthetic vitamin A analogue and the main metabolite of etretinate. It is considered to be the latest medicine prescribed to psoriasis patients. However, it is not used frequently because of its side-effect profile. Little is known about the Acitretin intestinal toxicity, so the objective of this study is evaluation of soriatane adverse events in daily practice treatment on the duodenum enterocytes of male rats. Two groups each of 10 Wistar male rats (5-6 weeks old), one of them is the treated group and the other is the control group. The drug was dissolved immediately in distilled water before administration, and given to treated rats by gastric intubation in the morning $(0.2$ $\mathrm{mg} / \mathrm{kg} /$ day for 12 months), while the control group received only distilled water. A significant reduction in number and height of villi with increased mucosal thickness. Damage in the duodenum tissues with villi fusion, distortion flattened epithelial cells; intense lamina propria and edema were observed. The ultra-structure alterations were indicated by Golgi apparatus, rough endoplasmic reticulum and mitochondrial atrophy with cristiolysis. Proliferation of smooth endoplasmic reticulum, nuclear deformity and increased number of liposomes were also noted. It may concluded that Soriatane led to irreversible ultra- structural alterations in rat enterocytes after 12 months treatment and precautions should be taken in prescribing acitretin to patients.
\end{abstract}

Keywords: Soriatane; Psoriasis; Enterocytes; Histopathology; Ultrastructure

\section{Introduction}

Soriatane (Acitretin) is a systemic retinoid and a time-honored treatment for psoriasis and some keratinization disorders [1,2]. It normalizes cellular differentiation and maturation, and it is used also as a chemo-preventive agent against cutaneous malignancies. However, it is not used frequently because of its side-effect profile [3]. There is no safe minimal dose of soriatane (acitretin) for use, a small amounts of acitretin can be converted into etretinate, which is 50 times more lipophilic and has a slower elimination half-life (from 80 to 175 days) [4,5]. After oral administration, its absorption may vary between individuals (from 36 to 95\%) and elimination occurs by hepatic and renal paths [5]. The most serious adverse effect of soriatane is teratogenicity [5-7]. While, its long-term treatment caused side effects on vital body organs and fetus [8] and may cause hepatitis, nephritic and hepatic histopathological alterations [5,9-11].

Moreover, the metabolites of soriatane drug have side effects on stomach and intestine [12] and cause nausea, vomiting, diarrhea, abdominal pain [13]. There are inadequate histological studies on the effect of the soriatane in the intestinal tissue, hence, the present work aimed to evaluate toxicity of oral soriatane therapy on duodenum tissue in male rats.

\section{Materials and Methods}

\section{Drug}

Acitretin (Neotigason') is a second generation synthetic retinoid and monoaromatic agent that has substituted etretinate (Tigason') in the treatment of psoriasis. Some commonly used brand names are in the U.S and Canada Soriatane. Other commonly used names are 13cis acitretin, etretin, and isoetretin. Available in $10 \mathrm{mg}, 17.5 \mathrm{mg}, 22.5$ $\mathrm{mg}$, and $25 \mathrm{mg}$ gelatin capsules for oral administration. Chemically, acitretin is all-trans-9-(4-methoxy-2,3,6-trimethylphenyl)-3,7-dimeth- yl-2,4,6,8-nonatetraenoic acid. It is a yellow to greenish-yellow powder with a molecular weight of 326.44 . The structural formula is (Structure $1)$ :<smiles>COc1cc(C)c(/C=C/C(C)=C/C=C/C(C)=C/C(=O)O)c(C)c1C</smiles>

Each capsule contains acitretin, microcrystalline cellulose, sodium ascorbate, gelatin, black monogramming ink and maltodextrin (a mixture of polysaccharides) $[2,5,14]$.

\section{Tested animals}

Twenty adults Wistar male rats (Rattus norvegicus albinus), average weight about $220 \pm 7.5 \mathrm{~g}$, were used in this study. According to Krinke [15] and Rollman et al. [16] Wistar male rats Rattus norvegicus albinus will be the logical strain point for histological research. Animals were supplied by King Fahd Medical Researcher Center of Saudi Arabia, placed in suitable cages, maintained in constant temperature at $17^{\circ}$ $21^{\circ} \mathrm{C}$, with proper humidity (about $60 \%$ ) and illumination following the pattern of day and night. They were fed with industrial standard diet formulation and water ad libitum. Rats were randomly divided into two groups each group contained ten rats as follows: Group 1-

*Corresponding author: Laila A. Hummadi, Biology Department, Science Faculty for Girls, King Abdul-Aziz University, Jeddah, Saudi Arabia, E-mail: lylaa_alhumadi@windowslive.com

Received November 08, 2011; Accepted February 22, 2012; Published February 27, 2012

Citation: Hummadi LA (2012) Adverse Effects of Soriatane on Rats Enterocytes: Light Microscopy and Ultrastructural Studies. J Cytol Histol 3:133. doi:10.4172/21577099.1000133

Copyright: (c) 2012 Hummadi LA. This is an open-access article distributed under the terms of the Creative Commons Attribution License, which permits unrestricted use, distribution, and reproduction in any medium, provided the original author and source are credited. 
Citation: Hummadi LA (2012) Adverse Effects of Soriatane on Rats Enterocytes: Light Microscopy and Ultrastructural Studies. J Cytol Histol 3:133. doi:10.4172/2157-7099.1000133

Page 2 of 5

control rats, they were orally given distilled water during the period of the experiment. Group 2- drug-treated rats were given single morning dose of $(25 \mathrm{mg} / \mathrm{kg} 7$ days/week) according to Goodman and Gilman [17] and calculated to rats weight $(0.2 \mathrm{ml} / \mathrm{kg})$ according to Paget and Darnes [18]. The doses were given via a stomach tube for 12 months according to OECD guideline [19] and Derelanko \& Hollinger [20] and Hayes [21] on the design and conduct of chronic toxicity and carcinogenicity studies. During the experiment rats were observed for apparent signs of toxicity or behavioral alterations and body weight was weekly recorded. Rats were sacrificed 24 hours after the end of experimental period (12 months) by cervical decapitation.

\section{Histopathological and cytological studies}

$2-5 \mathrm{~cm}$ from the proximal part of the small intestine was taken from control and treated groups (7rats from each group) and fixed in $10 \%$ neutral buffered formalin and prepared for light microscopic examination [22]. For transmission electron microscope (TEM) small pieces from duodenum of both treated and control groups ( 3 rats from each group) were immersed in Karnowsky solution (4\% paraformaldehyde $+1 \%$ glutaraldehyde in a $0.1 \mathrm{M}$ sodium cacodylate buffer (7.4)) for two hours. The specimens were post-fixed in buffered $1 \%$ osmium tetroxide ( $\mathrm{pH} 7.4$ ) at $4 \mathrm{c}$ for 2 hours [23], dehydrated in a graded ethyl alcohol series, cleared in propylene oxide and embedded in epoxy resin [24]. Semi thin sections stained with toludin blue and examined with light microscope. Ultrathin sections were double stained with uranyl acetate and led citrate and photographed by electron microscope Philips-CM100 at King Fahd Medical Research / Jeddah, Saudi Arabia.

\section{Mucosal morphometrics}

Mucosal thickness (from the base of the muscularis mucosa to the villus tip), villus height (from the base to the tip of the villus), and number of villi were determined per square millimeter on individual intestinal segments at ten separate microscopic fields for each animal section of tissue $\mathrm{H}$ \& $\mathrm{E}$ stained using ocular micrometer-adapted light microscopy at a magnification of 40X, 100X [25]. The average and standard deviation for the treatment and control groups were calculated using the methods of statistical analysis t-test [26].

\section{Evaluation of histopathological lesions score in rat duodenum}

At the end of experiment, at least $10(\times 40)$ fields from each section per rat were examined from control and treated sections tissues, and recorded the degree of their damages by a semi quantitatively method using a four points scale according to Kocan et al. [27] method and the scale was:

(0) [None]no damage.

(1) [Scare] slightly damage.

(2) [moderate] mild degree of damage or in specific regions.

(3) [Severe] a high degree of damage and spread.

\section{Statistical analysis}

It was work carried out on each different variable for body and the degree of tissue damage (lesion scores), using the t- test program and one-way analysis of variance ANOVA. Differences were considered significant at $\mathrm{P}<0.05$. Using Windows SPSS 13.0 for statistical analysis of the data.

\section{Results}

The present work indicated significant reduction in the rats body weight after 12 months of the experiment in treated group (Table 1), as well as increased in the duodenum mucosal thickness with decreased villi number $/ \mathrm{mm}^{2}$ (Table 2).

The histological and ultrastructural examinations of the duodenum from control rats showed that the intestinal villi are covered with a single layer of columnar epithelial cells characterized by the presence of regular microvilli at the apical surface (Figures 1a, 2a). The core of each microvillus is filled with fine filaments that extend from the dense tip of the microvilli into the terminal web underlying the striated border. There are frequent invaginations of the plasma membrane at the base of microvilli. Junctional complexes composed of a tight junction, a desmosome, and a gap junction were seen between neighboring epithelial cells, and many desmosomes are present along the remainder of the lateral plasma membrane; in the deeper portions the adjacent lateral plasma membranes interdigitate to a considerable degree (Figure 3a). The cytoplasm of enterocytes is low electron density has widely scattered smooth-surfaced vesicles, and beneath the terminal web there are numerous mitochondria, electron-dense granules, smooth endoplasmic reticulum, multivesicular bodies, and mass of glycogen apically or basally to the rounded nuclei. The supranuclear cytoplasm contains short rough endoplasmic cisternae, scattered granules, and Golgi complexes (Figures 2a-d, 3a).

By using light microscope indicated that changes in the mucosal villi were in two patterns: The first form included villi fusion and loss in variable degrees associated with the duodenum mucosa epithelial atrophy (Figure 1b). Enterocytes disorganization and microvilli deterioration with disruption of desmosomes, terminal webs, tight junctions, and the lateral infolding were observed (Figures $3 \mathrm{~b}, \mathrm{c}$ ). In

\begin{tabular}{|l|l|l|}
\hline groups & Experimental periods & \\
\hline & Group I & Group II \\
\hline Odays & & \\
Mean & $220 \mathrm{~g}$ & -- \\
\hline S.E & \pm 7.5 & -- \\
\hline P & --- & \\
\hline 12 months & & \\
Mean & $376.1 \mathrm{~g}$ & $329.5 \mathrm{~g}$ \\
S.E & \pm 13.6 & \pm 10.29 \\
\hline P & --- & $0.002^{*}$ \\
\hline
\end{tabular}

*Significant $(P<0.05)$ by analysis of variance.

Mean \pm standard error of the mean.

Table 1: The mean body weight for control and treated adult male rats at the end of experimental period.

\begin{tabular}{|l|l|l|}
\hline & Group I & Group II \\
\hline Mucosal thickness $(\mathrm{mm})$ & $0.59 \pm 0.018$ & $0.67 \pm 0.031^{*}$ \\
\hline Villous height $(\mathrm{mm})$ & $0.27 \pm 0.035$ & $0.21 \pm 0.058^{*}$ \\
\hline No. of villi/mm2 & $27 \pm 0.047$ & $24 \pm 0.02^{*}$ \\
\hline
\end{tabular}

*Significant $(P<0.05)$ by analysis of variance.

Mean \pm standard error of the mean.

Table 2: Mucosal morphometrics for control and Acitretin adult male rats at the end of experimental period. 
Citation: Hummadi LA (2012) Adverse Effects of Soriatane on Rats Enterocytes: Light Microscopy and Ultrastructural Studies. J Cytol Histol 3:133. doi:10.4172/2157-7099.1000133

addition to, the intestinal mucosa invasion by macrophages (Figure 3d), polymorphism nuclei of necrotic enterocytes with condensed peripheral chromatin, and seemly lock nuclear pores were found (Figure 4a). The mitochondria appeared atrophy and cristiolysis, while, rough endoplasmic reticulum (RER) were fragmented, degranulated and atrophied. Clear proliferation of smooth endoplasmic reticulum (SER), and increased ribosomal granules also noted (Figure $4 \mathrm{~b}$ ).

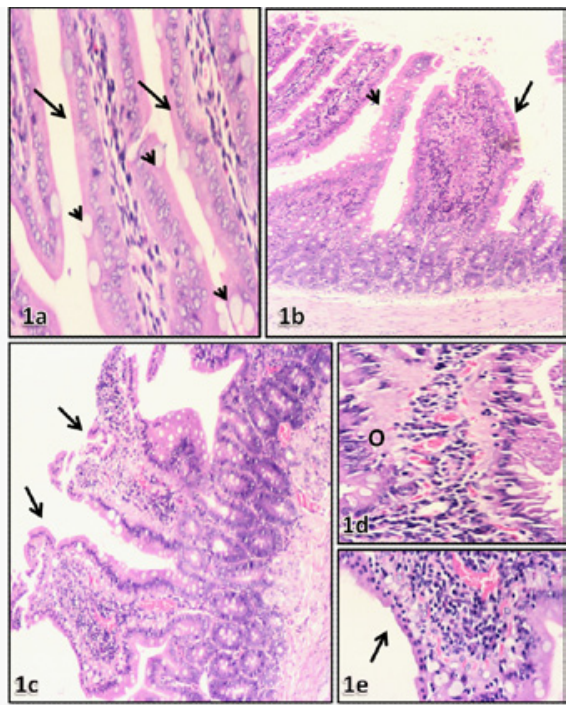

Figure 1: A) Transverse section of duodenum from control rats: showing the villi covered with two cell types: a single layer of columnar epithelial cells (enterocytes) (arrows) and goblet cells (head arrows). H\&E,X1000.

B-E) Transverse sections of duodenum from soriatane treated rats: (b) showed decrease in number of villi, fusion of villi ( arrow), atrophy (head arrow),.H\&E,X400. (c) villi stunting (arrows).H\&E.X400. (d) edematous (o) of the lamina propria. H\&E. X1000. (e) flattening of the epithelial cells with villus core inflammation and villi distortion. H\&E. X 1000.

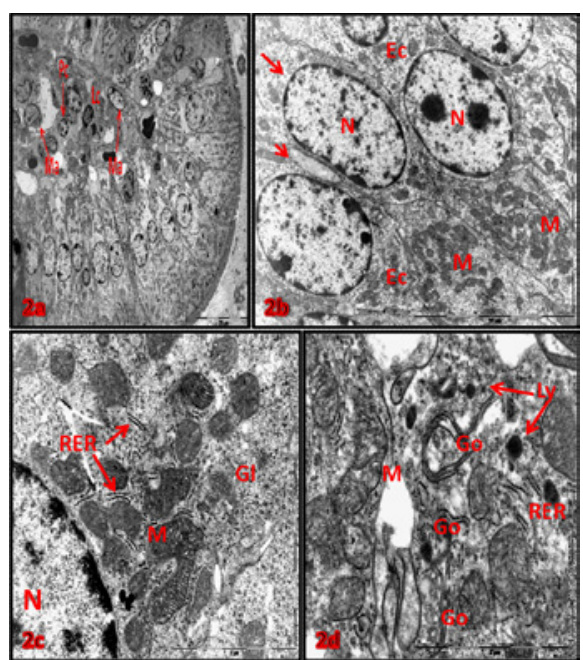

Figure 2: A-D) Electron micrographs of duodenum from control rats: (a) villus central core, macrophages (Ma), lymphocyte (Lc), and plasma cell (Pc).X1450. (b) columnar enterocytes $(\mathrm{Ec})$ with rounded nuclei(N) and mitochondria (M), note; lateral infolding (head arrows) filled with a flocculent material. X2600. (c) low electron density of enterocyte cytoplasm, short cisternae of rough endoplasmic reticulum (RER) closely associated with mitochondria (M), a mass of glycogen granules $(\mathrm{Gl})$ apically to the nucleus (N). X19000. (d) Golgi apparatus (Go), also note, mitochondria(M), RER and primary lysosomes (Ly). X25000.

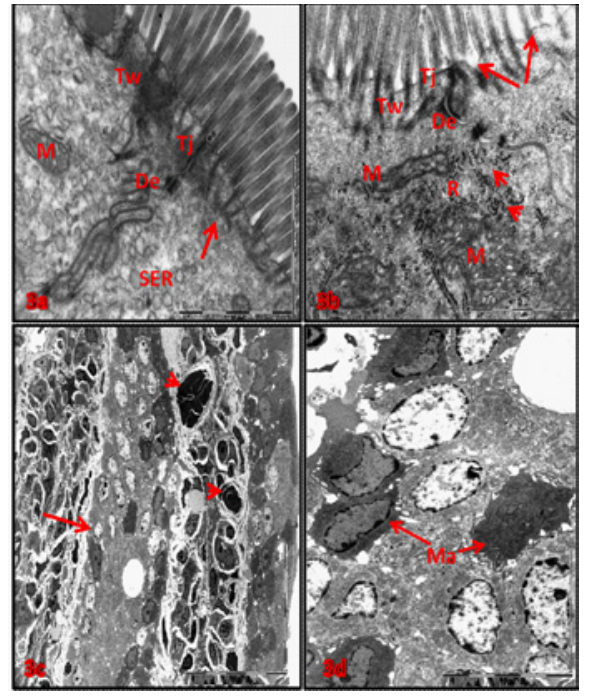

Figure 3: A) Electron micrographs of control enterocyte showed microvilli terminal web (Tw),tight junction (Tj), desmosomes (De), small widely scattered smooth-ER(SER) and mitochondria (M). X19000.

B-D) Electron micrographs of doudenum from soriatane treated rats (b) fusion villi and lose their brush border, enterocytes disorganization (arrow). X850. (c) higher magnification of figure (a) showed macrophages migration (Ma) through mucosa layer. X2600. (d): electron dens necrotic mitochondria(M),fragmentation and degranulation of rough ER (head arrows), increased ribosomal numbers $(R)$, deformed desmosomes (De),terminal web (Tw), tight junction (Tj), with affected microvilli (arrows). X19000.

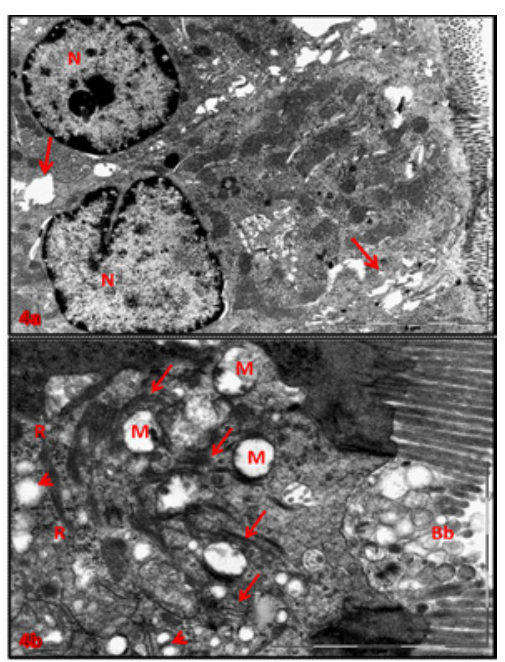

Figure 4: A, B) Electron micrographs of soriatane treated enterocytes: (a) disruption of lateral infoldings (arrows), and nuclei $(\mathrm{N})$ polymorphism of necrotic enterocytes with increase peripheral chromatin ,lose nuclear pores, X5800. (b) microvilli deterioration $(\mathrm{Bb})$, mitochondrial cristiolysis (M), SER proliferation (head arrows), degranulation and atrophied of RER(arrows), increased ribosomal numbers (R). X19000.

The second form of enterocytes acitretin toxicity was severe villi shortening with villi core edematous and architectural distortion which displayed a flattened epithelial cell with ultra-structural abnormalities (Figures 1c-e). Hence, the flattened cells showed evidence of cellular injury, such as prominence of vacuolar degeneration, nuclear deformity, irregular nuclear membrane, high electron density of necrotic mitochondria, and increased in number of liposomes (Figures 
Citation: Hummadi LA (2012) Adverse Effects of Soriatane on Rats Enterocytes: Light Microscopy and Ultrastructural Studies. J Cytol Histol 3:133. doi:10.4172/2157-7099.1000133

5a-c). In addition, a severe inflammation with increased number of neutrophils, macrophages, plasma cells, lymphocytes have been observed (Figure 5d).

\section{Evaluation of histopathological lesions scores}

The histopathological scores are abstracted in table 3 . The villi shortening, fusion and cellular infiltration were highly significantly $(\mathrm{p}$ $<0.01$ ) increased in the soriatane treated-duodenum when compared to the villi loss and microvilli damage scores.

\section{Discussion}

The present results suggest that decreased body weight following long-term exposure to soriatane may underlie the reduced food appetite, emaciated and developed diarrhea or bloody diarrhea which observed in $78 \%(7-8 / 10)$ or $23 \%(2-3)$ of animals respectively. Similar findings were noted previously on rats received acitretin drug [9-11]. However, Shen et al. [28] suggested that the enzymes of the gut wall may represent an important and highly sensitive site of metabolicallybased interactions for orally administered drugs. This indicate that the soriatane administration changed fecal flora which led to the functional disturbance of the intestinal epithelium, as expressed by

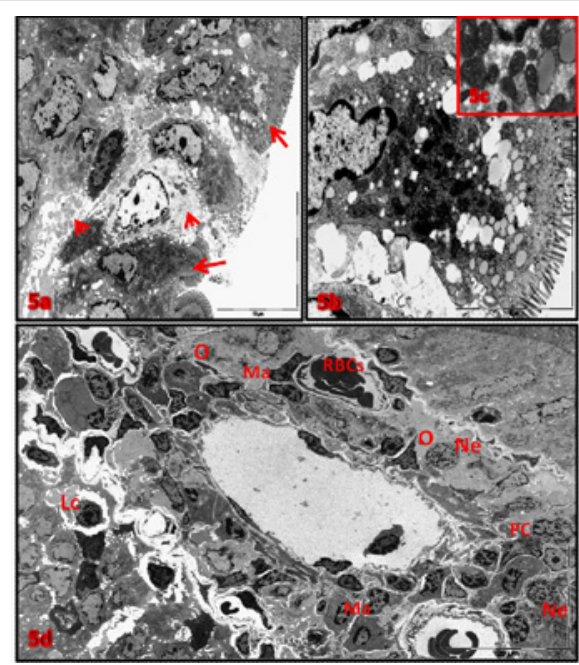

Figure 5: A-D) Electron micrographs of villi from soriatane treated mucosa: (a) cytoplasmic degeneration (head arrows) and necrotic enterocytes (arrows). X4600. (b) necrotic enterocyte containing electron dens atrophied mitochondria, necrotic nucleus with irregular nuclear membrane and increased number of liposomes. X7900. (c) higher magnification of figure (b) showed atrophied mitochondria and membranous lipid vacuoles. X25000. (d) villus core: showed capillary expanded and congestion, edema(O), increased number neutrophils(Ne), macrophages(Ma), plasma cells $(\mathrm{Pc})$ and lymphocytes (Lc). X1450.

\begin{tabular}{|l|c|c|}
\hline & Control group & Soriatane -treated group \\
\hline Villus loss & $0.07 \pm 0.32$ & $2.52 \pm 0.71^{*}$ \\
\hline Villus shortening & $0.03 \pm 0.42$ & $3.40 \pm 0.70^{* *}$ \\
\hline Villus fusion & $0.06 \pm 0.32$ & $2.70 \pm 0.68^{* *}$ \\
\hline Microvilli damage & $0.07 \pm 0.32$ & $2.50 \pm 0.53^{*}$ \\
\hline Cellular infiltration & $0.10 \pm 0.12$ & $2.70 \pm 0.80^{* *}$ \\
\hline
\end{tabular}

${ }^{*}$ Significant $(P<0.05)$ high significant ${ }^{* *} p<0.01$.

L.S. 0: non; 1: scare; 2: moderate; 3: sever; No. of individual $=7$

Table 3: Scoring values of the damage in the histopathological analysis of the experimental groups. reduced enzymic activity of the enterocytes and may present a key factor in the development of the pathophysiological events [29]. Hence, hypertrophied of mucosal layer may be due to increased scores of inflammation and edematous tissue.

The present results agree with some studies using light and electronic transmission microscopy described normal rats duodenum histology [30-33]. The recent histological findings in villi were atrophy, loss of normal architecture, necrosis associated by congestion of blood vessels, edema and inflammation. Similar results were reported in liver and kidney tissues of rats received oral acitretin for three months [9-11]. Van Ditzhuijsen et al. [34] indicated severe histological manifestations followed treatment with acitretin in a 50-year-old female. The vacuolations of enterocytes observed in this work was confirmed by Cheville [35] who conducted that these cytoplasmic vacuoles are responsible for collecting the injurious elements and preventing them from interfering with the biological activities of cells. Furthermore Sanad et al. [36] suggested that the cellular degeneration might be attributed to liberation of acid hydrolysis released from the destructed lysosomes to facilitate the process of autolysis. It was evident that the degenerative changes appeared earlier in the cytoplasm than in the nuclei, which explained that the nuclear damage is a sequence of cytoplasmic damage [37]. Corresponding to current study, some clinical studies have shown that retinoids bind to nuclear receptors, altering the expression of a variety of genes [5-7], which led to functional efficiency of the cells nuclei [38]. The pathological changes in mitochondria have been fully documented in rodents as swollen or atrophy [39]. The mitochondrial cavitations could be an important indicator of cellular damage leading to loss of functional efficiency. Moreover, the mitochondrial destruction may be due to disturbance of calcium ions $\mathrm{Ca}^{+2}$ into cells [40], or block the ATP synthesis [41], or may be due to loss of mitochondria membrane permeability [42] or change the cellular $\mathrm{pH}$ [43]. Ghadially [38] reported that rough ER swelling or atrophy may reflecting the change of function activity. While, in early stages of cytotoxicity the reproduction or proliferation of smooth ER by oxidative effort can be shown to counter the adverse effects associated with an increase of detoxification enzymes $[44,45]$. Several studies have shown that encapsulation of a potent immunosuppressive drug within a lipid bilayer to form liposomes can alter its bio-distribution profile and half-life [46]. Hence, this explains increased liposomal number in affected enterocytes. The cellular infiltration of the lymphocytes and macrophages could be signs of chronic inflammation [35,47], where macrophages engulfed the causes of damage and injuries tissues while lymphocytes produce anti-toxins and accelerate cell healing [45,47]. Additionally, Zhou [48] revealed the integrity of the intestinal epithelial barrier plays a crucial role in maintaining symbiotic homeostasis between microbes in the gut lumen and eukaryotic cells. Disruption of intestinal epithelial barrier function occurs commonly under various pathological conditions, including trauma, inflammatory bowel disease, and drug-induced gastrointestinal toxicity, exhibiting increased intestinal epithelial paracellular permeability or "leakiness" of the intestinal mucosa. Cheville [35] confirmed that activation of macrophages occurs in the presence of particulate material and strong microbial antigens.

\section{Conclusion}

In the experimental model using Wister male rats (Rattus norvegicus albinus), the dose of $25 \mathrm{mg} / \mathrm{kg} /$ day administered by the oral route for long therapy have been proved to be induction of gastrointestinal adverse effects. The above findings have not yet been 
Citation: Hummadi LA (2012) Adverse Effects of Soriatane on Rats Enterocytes: Light Microscopy and Ultrastructural Studies. J Cytol Histol 3:133. doi:10.4172/2157-7099.1000133

Page 5 of 5

described earlier, which represent a useful model for investigation the side effects of Soriatane. The safety profile of oral Soriatane appears to be well established, although rare new side effects are occasionally reported. Appropriate patient selection, use of the lowest required dose, and adequate follow-up are significant factors in the prevention of these toxicities.

\section{References}

1. Booij MT, Van De Kerkhof PC (2011) Acitretin revisited in the era of biologics. J Dermatolog Treat 22: 86-89.

2. Nikam BP, Amladi S, Wadhwa SL (2006) Acitretin. Indian J Dermatol Venereol Leprol 72: 167-172.

3. Pang ML, Murase JE, Koo J (2008) An updated review of acitretin--a systemic retinoid for the treatment of psoriasis. Expert Opin Drug Metab Toxicol 4: 953964.

4. Saurat JH (1999) Retinoids and psoriasis: novel issues in retinoid pharmacology and implications for psoriasis treatment. J Am Acad Dermatol 41: S2-6.

5. Berbis $P$ (2001) [Acitretine]. Ann Dermatol Venereol 128: 737-745.

6. Brecher AR, Orlow SJ (2003) Oral retinoid therapy for dermatologic conditions in children and adolescents. J Am Acad Dermatol 49: 171-182.

7. Yamauchi PS, Rizk D, Kormeili T, Patnaik R, Lowe NJ (2003) Current systemic therapies for psoriasis: where are we now? J Am Acad Dermatol 49: S66-77.

8. Macleod J, Edwards C, Bouchier I (2001) Davidson's Principles and Practice of Medicine. Fifteenth Ed Livingstone Churchill New York 348.

9. AL-elyani R, Kalifa S, EL-hummdi L, AL-eryani F (2008) The protective role of Ginger and Camel's milk on toxic effect of Acitretin (Neotigason) in liver tissue of albino rats. J Egypt Ger Soc (Zool) 55: 85-108.

10. Camuto P, Shupack J, Orbuch P, Tobias H, Sidhu G, et al. (1987) Long-term effects of etretinate on the liver in psoriasis. Am J Surg Pathol 11: 30-37.

11. EL-hummdi LA, AL-elyani R, Kalifa S, AL-eryani (2007) Histological study on the effect of camel's milk on kidney of male albino rats treated with Acitretin drug. Egyptian Society of Biotechnology and Environmental Sciences 9: 1-19.

12. Katz HI, Waalen J, Leach EE (1999) Acitretin in psoriasis: an overview of adverse effects. J Am Acad Dermatol 41: S7-S12.

13. Lebwohl M, Ali S (2001) Treatment of psoriasis (Part 2) Systemic therapies. J Am Acad Dermatol 45: 649-661.

14. FDA (2011) U.S Food and Drug Administration: Soriatane Medication Guide.

15. Krinke GJ (2000) History, Strains and Models. The Laboratory Rat (Handbook of Experimental Animals). Gillian R. Bullock (series ed.), Tracie bunton (series ed.). Academic Press 3-16.

16. Rollman GB, Lautenbacher S, Jones KS (2000) Sex and Gender differences in responses to experimentally induced pain. In: Fillingim RB (Ed) Sex, gender and pain; progress in pain research and management, Seattle; International Association for the study of pain, 165-190.

17. Goodman A, Gilmans G (2006) The Pharmacological Basis of Therapeutics (10th ed.) Medical Publishing Division, 2147.

18. Paget GE, Darnes JM (1964) Evaluation of drug activities and Pharmacokinetics academic press 1: 135-136.

19. OECD (2010) OECD Draft Guidance Document $N^{\circ} 116$ on the Design and Conduct of Chronic Toxicity and Carcinogenicity studies, supporting TG 451, 452, 453.

20. Derelanko MJ, Hollinger MA (1995) CRC Handbook of Toxicology. CRC Press, Boca Raton, Florida.

21. Hayes AW (1994) Principles and Methods of Toxicology. (3rd Edition), Raven Press, New York.

22. Bancroft JD, Gamble M (2002) Theory and practice of histological techniques. Ahrcourt Health Sciences Company. Churchill. (5th ed.) Harcourt publishers Limited 130-132.

23. Leite Junior R, Mello NB, Pereira Lde P, Takiya CM, Oliveira CA, et al. (2010) Enterocyte ultrastructural alterations following intestinal obstruction in rats. Acta Cir Bras 25: 2-8

24. Woods AE, Stirling JW (2002) Electron microscopy: techniques. Ed. Bancroft JD, and Gamble M, 5th ed. Harcourt Publishers, 31.
25. Gurbuz AT, Kunzelman J, Ratzer EE (1998) Supplemental dietary arginine accelerates intestinal mucosal regeneration and enhances bacterial clearance following radiation enteritis in rats. J Surg Res 74: 149-154

26. Fisher RH, Yates $F$ (1948) Statistical tables for agricultural, biological and medical research. Oliver and Edinburgh, 320.

27. Kocan RM, Marts GD, Okihiro MS ,Brown ED, Baker T (1996) Reproductive success and histopathology of individual prince william sound pacific herring 3 year after the Exxon valdez oil spill. Can J Fish Aquat Sci 53: 2388-2393.

28. Shen DD, Kunze KL, Thummel KE (1997) Enzyme-catalyzed processes of firstpass hepatic and intestinal drug extraction. Adv Drug Deliv Rev 27: 99-127.

29. Kozakova H, Hanson LA, Stepankova R, Kahu H, Dahlgren UI, et al. (2003) Vitamin A deficiency leads to severe functional disturbance of the intestinal epithelium enzymes associated with diarrhea and increased bacterial translocation in gnotobiotic rats. Microbes Infect 5: 405-411.

30. Coulombre AJ, Coulombre JL (1958) Intestinal development. I. Morphogenesis of the villi and musculature. J Embryol Exp Morphol 6: 403-411.

31. Dunn JS (1967) The fine structure of the absorptive epithelial cells of the developing small intestine of the rat. J Anat 101: 57-68.

32. Hayward AF (1967) Changes in fine structure of developing intestinal epithelium associated with pinocytosis. J Anat 102: 57-70.

33. Sohma M (1983) Ultrastructure of the absorptive cells in the small intestine of the rat during starvation. Anat Embryol (Berl) 168: 331-339.

34. van Ditzhuijsen TJ, van Haelst UJ, van Dooren-Greebe RJ, van de Kerkhof PC Yap SH (1990) Severe hepatotoxic reaction with progression to cirrhosis after use of a novel retinoid (acitretin). J Hepatol 11: 185-188.

35. Cheville NF (2009) Ultrastructural pathology: The comparative cellular basis of disease (2nd ed.) Wiley-Blackwell. A John Wiley of Sons, Inc USA.

36. Sanad SM, El-Nahass EM, Abdel Gawad AM, Al Deeb AM (1997) Histologic effects of sodium barbitone on the liver of mice. J Egypt Ger Soc Zool (Histo Histochem) 22: 1-16.

37. Abdel Hameed TF (2004) Light and electron microscopic studies on the effect of orally administered formalin on liver and kidney of guinea pig. J Egypt Ger Soc Zool (Histol. Histochem) 45: 203-224.

38. Ghadially FN (1988) Ultra structure pathology of the cell and matrix. A text and Atlas of physiological and pathological altrerations in cell fine structure Butterworth London and Boston, 790.

39. Robbins C (1995) Pathological Basis of Disease (5thEd.) International edition W B Sounder S Poli G (2000) Pathogensis of liver fibrosis: role of oxidativestress. Mol Aspects Med 21: 49-98.

40. Pan Z, Bhat MB, Nieminen AL, Ma J (2001) Synergistic movements of $\mathrm{Ca}(2+)$ and Bax in cells undergoing apoptosis. J Biol Chem 276: 32257-32263.

41. Mikhailov V, Mikhailova M, Pulkrabek DJ, Dong Z, et al. (2001) Bcl-2 prevents Baxoligomerization in the mitochondrial outer membrane. J Biol Chem 276 : 18361-18374.

42. Smaili SS, Hsu YT, Sanders KM, Russell JT, Youle RJ (2001) Bax translocation to mitochondria subsequent to a rapid loss of mitochondrial membrane potential. Cell Death Differ 8: 909-920.

43. Tafani M, Cohn JA, Karpinich NO, Rothman RJ, Russo MA, et al. (2002) Regulation of intracellular $\mathrm{pH}$ mediates Bax activation in HeLa cells treated with staurosporine or tumor necrosis factor-alpha. J Biol Chem 277: 49569-49576.

44. Manov I, Motanis H, Frumin I, Iancu TC (2006) Hepatotoxicity of antiinflammatory and analgesic drugs: ultrastructural aspects. Acta Pharmacol Sin 27: $259-272$

45. Hummdi LA, Habashi SH (2010) Histological and Ultra- structure studies on the Liver Changes Induced by Xefo Drug (Lornoxicam) of Adult Female Mice. Middle East \& North Africa Journal of Animal science 3: 551-575.

46. Yang H, McAlister VC, Al-Jazaeri A, Wright JR Jr (2002) Liposoma encapsulation significantly enchances the immunosuppressive effect of tacrolimus in a discordant islet xenotransplant model. Transplantation 73: 710 713.

47. Curran RC (1996) Colour atlas of histopathology. (3 ${ }^{\text {rd }}$ Edn), Oxford university press. New York, 280.

48. Zhou H (2011) HIV protease inhibitors induce endoplasmic reticulum stress and disrupt barrier integrity in intestinal epithelial cells. Methods Enzymol 490: 107-119. 